\title{
Cavernous hemangioma of the cervix and pregnancy: a case report
}

\author{
Samar Elkhateb ${ }^{1,2^{*}}$, Mostafa Azzouzi Idrissi ${ }^{2}$, Kamilia Laabadi $^{1,2}$, Leila Chbani ${ }^{2,3}$, Hikmat Chaara ${ }^{1,2}$, \\ AbdIlah Melhouf ${ }^{1,2}$ \\ ${ }^{1}$ Department of Gynaecology and Obstetrics II, University Hospital Hassan II, Sidi Mohamed Ben Abdellah University, Fez, Morocco; \\ ${ }^{2}$ Sidi Mohamed Ben Abdullah University, Fez, Morocco; \\ ${ }^{3}$ Department of Pathology, University Hospital Hassan II, Sidi Mohamed Ben Abdullah University, Fez, Morocco. \\ Email: ${ }^{*}$ elkhatebsamar@yahoo.fr
}

Received 5 June 2011; revised 24 July 2011; accepted 10 August 2011.

\section{ABSTRACT}

Purpose: Cavernous haemangiomas of the uterine cervix are very rare and usually harmless. It is a benign tumor that may cause gynecological obstetrical complications. Although it is a benign condition but it can have serious consequences for the mother as well as for the baby. The treatment is often surgical and diagnosis is histological. Methods and Result: we reported a case of cavernous haemangioma of the cervix in a 25-year old multiparous patient, referred to our Centre in the 33 - 34 gestational weeks for premature labor with membranes rupture. A $3 \mathrm{~cm} \times 6 \mathrm{~cm}$ soft regular purplish red mass is found in the uterine cervix. Tocolosys, prophylactic antibiotic therapy and corticotherapy for fetus pulmonary maturation were then decided after elimination of chorioamniotite signs. Caesarean has been made during labor, a week later, for tumor previa. The tumor excision has been made through the vagina after fetus extraction. The histological examination confirmed diagnosis of the cavernous haemangioma. Discussion: Further to this observation, the clinical, histological and therapeutic characteristics of the cavernous haemangioma unusual presentation were drawn up and literature enriched since this pathology is rare. Most previous reports in the literature consist of single-case histories, and the experience of individual institutions is limited. The patients dramatically present dilemmas in the disease management. This can result in uncontrolled bleeding especially during operative delivery and may require hysterectomy. To avoid unexpected bleeding from haemangioma, patients should be repeatedly examined for haemangioma of the birth canal, and special care shouId be taken in choosing the delivery mode.

Keywords: Cavernous Haemangioma; Uterine Cervix;
Pregnancy; Tocolytic Therapy

\section{INTRODUCTION}

Cavernous haemangioma of uterine cervix is a rare vascular malformation. It is a benign pathology. Its seat is primarily visceral and generally hepatic [1,2-4]. This cervical lesion may cause vaginal metrorrhagia or pains [1,2-9]. It seems that the tumor can vary. The differenttial diagnosis includes a cervical malignant tumor. The anatomopathologic study proves the benign and vascular nature of the tumor [10]. The treatment is generally surgical [1,2]. Many gynecological and/or obstetrical complications are often associated. The gynecological complications are inter-menstrual spotting, menometrorrhagia, post-menopause metrorrhagia, post coitus metrorrhagia, infertility and dyspareunia [1-2,7-9]. The obstetrical complications are the premature rupture of membranes, the fetal death in the uterus, the postpartum haemorrhage and disseminated intravascular coagulation [3-5,11-13]. The dilemma that may arise is the delivery way in a pregnant mother having a cervical cavernous haemangioma [3-17]. In this report, we describe a haemangioma of the uterine cervix in a 25 -year old multiparous patient, who presented premature labor with membranes rupture in the 33 - 34 gestational weeks. Caesarean has been made during labor, a week later, for tumor previa. The tumor excision has been made through the vagina after fetus extraction. The histological study confirmed diagnosis. Apparently, the reported case emphasizes the importance of special care in the choice of the delivery mode. This case is presented in order to increase awareness on the existence of Cavernous haemangioma of the uterine cervix during pregnancy, which may cause life-threatening bleeding at the delivery time and obstetrical complications. 


\section{CASE REPORT}

Mrs. S.Z, 25 year-old, multiparous, G6 P2 1EV with two late abortions, referred to our Centre for premature rupture of the membranes at eight-month pregnancy. The clinical examination objectivized a $3 \mathrm{~cm} \times 6 \mathrm{~cm}$ soft regular purplish red mass, overhanging through the vulva. At the vaginal touch, this formation expands to the cervix anterior lip. At the obstetrical examination, several parameters are found: The fundal height at $26 \mathrm{~cm}$, Fetal Heart Beat, beginning uterine contractions associated to modifications in the uterine cervix and Bishop scores less than or equal to 4 . An obstetrical ultrasonography evaluated the pregnancy at the $34^{\text {th }}$ week of amenorrhea with the fetus weight estimated at 2508 grams. The maturity signs are absent and placenta is localized on the anterior fundic wall. Nifedipine tocolysis, prophylactic antibiotic therapy and antenatal corticosteroids for fetal lung maturation were then decided after elimination of Chorioamniotic signs. One week later, the patient entered in the active phase of labor. A caesarean was decided because of the previa obstacle. The new born child is a female premature, at 33 weeks - 34 weeks of amenorrhea, Apgar score at 8/10, with a birth weight of $2350 \mathrm{~g}$. After fetus extraction, the tumor excision, at the edge of the cervix, through the vagina was carried out (Figure 1).

The anatomopathological study of the piece revealed the cavernous haemangioma. The Histological analysis detects a benign tumor growth, without normal cervical stroma, made up from vascular grooves, of various sizes, full of blood. The walls of these grooves are very fine, composed of regular and flattened endothelium, and resting directly on neighboring fibrous tissue (Figure 2).

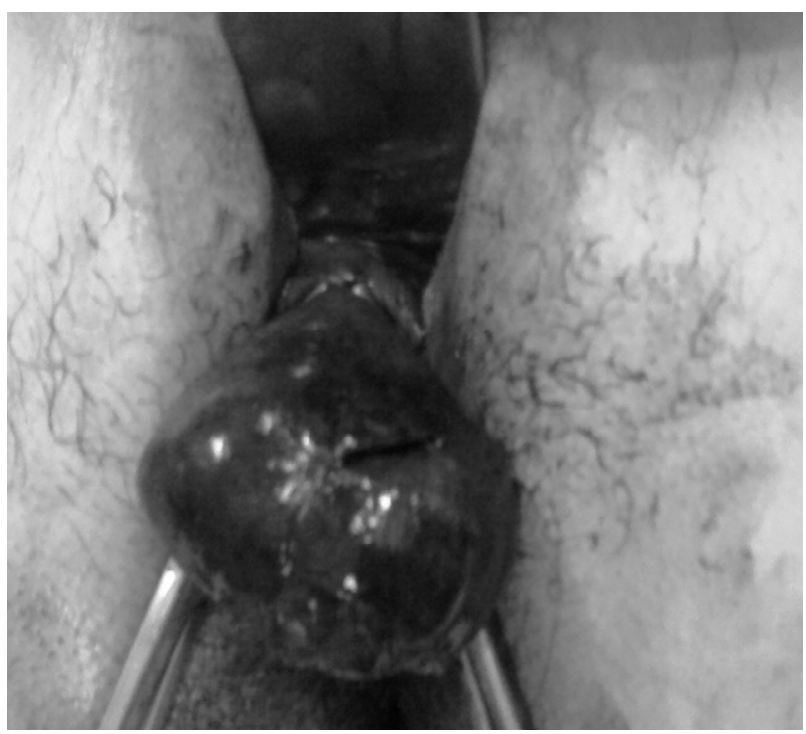

Figure 1. Soft regular purplish-red mass overhanging through the vulva.

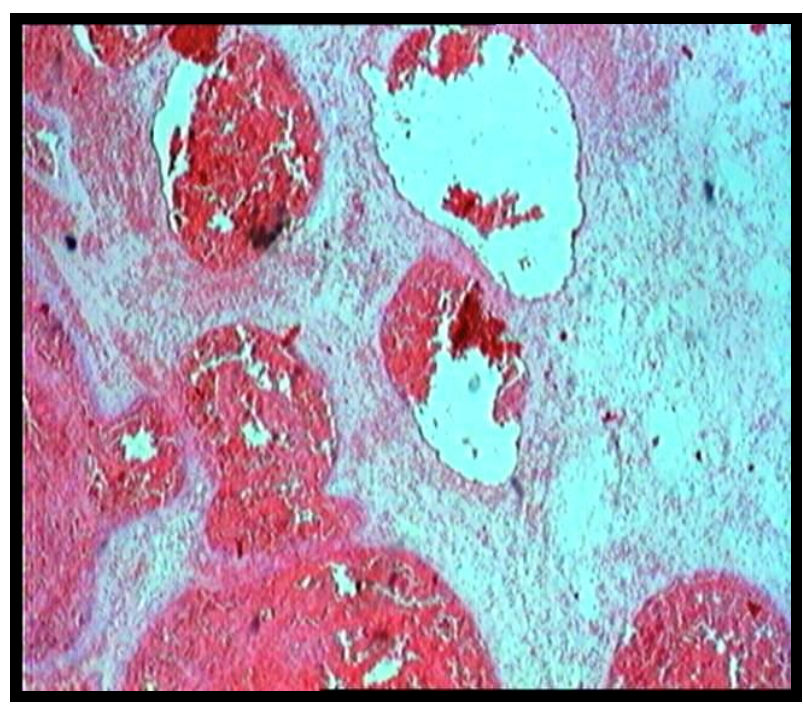

Figure 2. Fibrous tissue containing large cavities filled with blood and lined by regular endothelial cells.

\section{DISCUSSION}

The uterine cervix cavernous haemangioma is a vascular benign tumor growth primarily made up of superficial and/or deep dilated large blood-vessels. It can touch many internal organs such as the liver, the spleen, the pancreas, the gastrointestinal tract, the skin, the uterus and sometimes the brain. The cervical localization is rare [1-12]. In Table 1, we present 15 cases found in the literature. 5 cases are associated with pregnancy besides our case (Table 1).

Most cases in these series presented post-coitus metrorrhagias that were regarded as endocervical polyp in the clinical examination. These lesions were suspected to be malignant tumors at vaginal touch. Although the uterine cervix haemangioma is generally asymptomatic [7], $35 \%$ of the reported cases were associated to vaginal bleedings (menometrorrhagia, post-coitus metrorrhagia) $[8,18-20]$. Changes during pregnancy under hormonal influence can present a risk of obstetrical complications [8-13]. A quick growth of the lesion, during pregnancy, may generate premature rupture of membranes, premature Labor, fetal death in-utero, postpartum haemorrhage and disseminated intravascular coagulation [20]. These complications require delivery by Caesarean [13-17].

Surgical excision is curative in most of cases. Because the haemangioma is a benign vascular lesion with a high hemorrhagic risk, conservative therapies have been suggested such as the use of sclerosing agents, cryotherapy, and $\mathrm{CO}^{2}$ laser excision (carbon dioxide laser) [8]. The cervical haemangioma that especially presents serious complications, can be treated by local excision, conisation, or through ablation by laser [9-10]. These therapeutic methods permit to preserve fertility in the young 
Table 1. Review of various cases of the uterine cervix cavernous haemangioma in the literature.

\begin{tabular}{|c|c|c|}
\hline Ahern [18] & 1978 & Patient found to have cervical haemangioma on ultrasound, managed in a conservative way. \\
\hline Jackson [12] & 1993 & $\begin{array}{l}\text { Cervical haemangioma is diagnosed in an asymptomatic multiparous woman or during pregnancy, } \\
\text { expectant management is warranted. }\end{array}$ \\
\hline Petry [11] & 1994 & $\begin{array}{l}\text { 31-year old multiparous woman in the } 34+1 \text { gestational week, who presented herself with a fast growing } \\
\text { cervical haemangioma, indicates that this benign tumor may cause obstetrical complications. }\end{array}$ \\
\hline Padmanabhan [19] & 2001 & Oral Contraceptive Pills related cervical haemangioma and focal nodular hyperplasia of the liver. \\
\hline Riggs [20] & 2003 & $\begin{array}{l}\text { Patient presented intractable bleeding after Medical termination of pregnancy. Required hysterectomy } \\
\text { on Histopathology-cavernous haemangioma. }\end{array}$ \\
\hline Kondi-Pafiti [10] & 2003 & $\begin{array}{l}9 \text { unusual vascular tumors of the female genital tract and to investigate the problems in the differential diagnosis from } \\
\text { other genital lesions. A capillary haemangioma of the endometrium, one capillary and one cavernous haemangioma } \\
\text { of the cervix, } 6 \text { vulva lesions (one capillary, and one cavernous haemangioma and } 4 \text { angiokeratomas) and one } \\
\text { haemangiosarcoma of the mons pubis in a } 76 \text {-year-old patient were diagnosed. The differential diagnosis of the } \\
\text { vascular tumors must be made mainly from endometriotic lesions and melanomas. Immunohistochemistry } \\
\text { (S-100, CD31, CD34, CKS, EMA) aid in the Diagnosis. Local excision is appropriate for the benign vascular lesions. }\end{array}$ \\
\hline Baxi [7] & 2005 & $\begin{array}{l}\text { Haemangioma of the cervix was found in a } 60 \text {-year-old female patient with prolapse of uterus. The haemangioma } \\
\text { was incidentally detected during routine histopathological examination of the organ removed by surgery. }\end{array}$ \\
\hline Wang [9] & 2005 & $\begin{array}{l}\text { Examination of a } 39 \text {-year-old patient presenting pelvic pain revealed a noticeable pelvic mass consisting of a } 10 \mathrm{~cm} \\
\text { tumor extending from the cervix to the retro peritoneum. The pathology report demonstrated spindle cell } \\
\text { haemangioma. This is a rare case of spindle cell haemangioma of the cervix after transvaginal resection. }\end{array}$ \\
\hline Ozyer [8] & 2006 & $\begin{array}{l}\text { Reported a case of cavernous haemangioma of the cervix in a } 53 \text {-year-old patient complaining about } \\
\text { postcoital spotting. }\end{array}$ \\
\hline Tanaka [17] & 2007 & $\begin{array}{l}\text { The Patient has BRBNS, haemangioma of the uterine cervix appeared during pregnancy. } \\
\text { Caesarean section was performed without complications, One month after delivery, } \\
\text { cervical haemangiomas were found to have decreased in size. }\end{array}$ \\
\hline El Khateb & 2008 & $\begin{array}{l}25 \text {-year old multiparous patient in the } 33-34 \text { gestational week for premature labor with membranes rupture. A } 3 \mathrm{~cm} \\
\times 6 \mathrm{~cm} \text { soft regular purplish red mass is found in the uterine cervix. Caesarean has been made for } \\
\text { tumor previa interference. The tumor excision has been made through the vagina after caesarean. }\end{array}$ \\
\hline Reggiani Bonetti [6] & 2009 & $\begin{array}{l}3 \text { cases of haemangioma of the cervix in asymptomatic women, diagnosed as cavernous haemangioma. All } \\
\text { tumors were immunoreactive for CD } 31, \text { CD } 34 \text {, and factor-VIII-related antigen. Focal expression of } \\
\text { estrogen receptors was detected. No positivity was obtained with progesterone receptor antibodies. } \\
\text { The presence of estrogen receptor in the endothelial cells of the haemangioma of the cervix suggests } \\
\text { a direct role of this hormone in the haemangioma development. A possible target therapy is discussed. }\end{array}$ \\
\hline
\end{tabular}

female patients [1-5]. The surgical excision has always been essential to eliminate a subjacent malignant tumor, including malignant vascular lesions [10]. In gynecological practice, the embolization treatment for arteriovenous malformations was crowned with success in patients presenting serious menorrhagia with relief of symptoms and preservation of their capacity of reproduction [14]. However, the cervical haemangioma can be treated, if necessary, by hysterectomy $[15,18,20]$. Spontaneous regression of the lesion has been reported by Tanaka et al. [17].

The uterine cervix cavernous haemangioma is a rare lesion given its localization. The diagnosis of this benign tumor is histological. It is purely morphological and does not require any complementary technique. As in the case of other localizations, lesions are large-sized, less marked-out and often invading the underlying structures. They are inclined not to regress and require thus a sur- gical treatment to avoid bleedings, which are often frequent and sometimes important. In Histology, they are composed of dilated vessels, full of blood and lined with regular endothelial cells, without atypical mitoses. The vascular walls are sometimes thickened with adventitial fibrosis. Calcifications may also be present. The differrential histological diagnosis can be made if there is a benign lesion having a vascular component of reactional nature like the pyogenic or botryomycosis granuloma. However, the lesion polyploidy aspect, its lobule well marked-out character and the presence of abundant inflammatory infiltrate plead in favor of the reactional nature of the lesion [10-16].

The cervical cavernous haemangioma can also be found in particular cases of generalized vascular malformations such as Blue rubber bleb nevus syndrome (BRBNS), which is a rare disease showing venous malformations on the skin, on the gastro-intestinal tract and 
on other internal organs. Norifumi Tanaka reported the case of a patient who presented the BRBNS disease with the outbreak of several haemangiomas on the uterine cervix during pregnancy. A Caesarean was carried out. One month postpartum reduction in the size of the lesions was observed. The lesion, induced by pregnancy, increased during pregnancy and regressed after delivery [17].

Padmanabhan et al. reported the rare association of cavernous haemangioma of the cervix with the focal nodular hyperplasia of the liver in a patient using oral contraceptives [19].

Reggiani L et al. present three cases of cervix haemangioma in asymptomatic women, diagnosed as cavernous haemangioma in two cases and capillary haemangioma in one. All tumors were immune-reactive to CD31, CD34, and factor-VIII-related antigen. Focal expression of estrogen receptors was detected. No positivity was obtained with progesterone receptor antibodies. The presence of estrogen receptor in the cervix haemangioma endothelial cells suggests a direct role of this hormone in haemangioma development. A possible target therapy is discussed [6].

\section{CONCLUSIONS}

The uterine cervix cavernous haemangioma is a very rare pathology in pregnant women. This benign vascular lesion may cause gynecological-obstetrical complications. It is recommended to perform a Caesarean. Sometimes, the consequences could also be serious. Although, delivery by natural ways is possible but Caesarean is recommended. The differential diagnosis is very difficult because it is a rare lesion. Uterine atony or disseminated intravascular coagulation can be observed, likely to lead to hysterectomy. The final diagnosis can only be made via the histological study.

\section{REFERENCES}

[1] Gupta, R., Singh, S., Nigam, S. and Khurana, N. (2006) Benign vascular tumors of the female genital tract. International Journal of Gynecology Cancer, 16, 1195-1200.

[2] Gusdon, J.P. (1965) Haemangioma of the cervix four new cases and a review. American Journal of Obstetrics Gynecology, 91, 204-209.

[3] Virk, R.K., Zhong, J. and Lu, D. (2008) Diffuse cavernous haemangioma of the uterus in a pregnant woman: Report of a rare case and review of literature. Archives of Gynecology and Obstetrics, 279, 603-605. doi:10.1007/s00404-008-0764-7

[4] Talerman, A. (1967) Hemangioma of the ovary and the cervix. Obstetrics and Gynecology, 30, 108-113.

[5] Cherkis, R.C. and Kamath, C.P. (1988) Hemangioma of the uterine cervix and pregnancy: A case report. Journal of Reproductive Medicine, 33, 393-395.
[6] Reggiani Bonetti, L., Boselli, F., Lupi, M., Bettelli, S., Schirosi, L., Bigiani, N., Sartori, G. and Rivasi, F. (2009) Expression of estrogen receptor in haemangioma of the uterine cervix: Reports of three cases and review of the literature. Archives of Gynecology and Obstetrics, 280, 469-472. doi:10.1007/s00404-009-0928-0

[7] Baxi, S. (2005) Capillary haemangioma of the cervix-a case report. Indian Journal of Pathology and Microbiology, 48, 373-375.

[8] Ozyer, S., Uzunlar, O., Gocmen, M., Bal, S., Srvan, L. and Mollamahmutoğlu, L. (2006) Cavernous hemangioma of the cervix: A rare cause of vaginal bleeding. Journal of Lower Genital Tract Disease, 10, 107-108. doi:10.1097/01.lgt.0000210120.78145.b8

[9] Wang, Y.C., Chen, C.H., Su, H.Y., Li, H.S. and Liu, J.Y. (2005) Huge spindle cell hemangioma of the cervix-mimicking a pelvic tumor. Gynecologic and Obstetric Investigation, 60, 98-101. doi:10.1159/000085523

[10] Kondi-Pafiti, A., Kairi-Vassilatou, E., Spanidou-Carvouni, H., Kontogianni, K., Dimopoulou, K. and Goula, K. (2003) Vascular tumors of the female genital tract: A clinicopathological study of nine cases. European Journal of Gynaecological Oncology, 24, 48-50.

[11] Petry, K.U., Bernhards, J. and Jagla, K. (1994) Cavernous hemangioma of the uterine cervix in pregnancy. Geburtshilfe Frauenheilkd, 54, 62-64. doi:10.1055/s-2007-1023553

[12] Jackson, J. (1993) Natural history of a cervical cavernous hemangioma through two pregnancies. Journal of the American Board of Family Practice, 6, 283-287.

[13] Lovett, B.G. and Camden, N.J. (1959) Hemangioma of uterine cervix complicating pregnancy. American Journal of Obstetrics and Gynecology, 78, 424.

[14] Poppe, W., Van Assche, F.A., Wilms, G., Favril, A. and Baert, A. (1987) Pregnancy after transcatrher embolization of a uterine arteriovenous malformation. American Journal of Obstetrics and Gynecology, 156, 1179.

[15] Malhotra, S., Sehgal, A. and Nijhawan, R. (1995) Cavernous hemangioma of the uterus. International Journal of Gynecology and Obstetrics, 51, 159-160. doi:10.1016/0020-7292(95)02473-P

[16] Enzinger, F.M. and Weiss, S.W. (1995) Soft tissue tumors. Third Edition, The CV Mosby company, St Louis.

[17] Tanaka, N., Tsuda, M., Samura, O., Miyoshi, H., Hara, T. and Kudo, Y. (2007) Blue rubber bleb nevus syndrome: Report of a patient with haemangiomas of the vaginal portion of the cervix appearing during pregnancy. Journal of Obstetrics and Gynaecology Research, 33, 546 -548. doi:10.1111/j.1447-0756.2007.00568.x

[18] Ahern, J.K. and Allen, N.H. (1978) Cervical hemangioma: A case report and review of the literature. Journal of Reproductive Medicine, 21, 228-231.

[19] Padmanabhan, V., Mount, S.L. and Eltabbakh G.H. (2001) Cavernous hemangioma of the cervix in association with focal nodular hyperplasia of the liver: A case report. Journal of Reproductive Medicine, 46, 1067-1070.

[20] Riggs, J., Bertoni, M., Schiavello, H., Weinstein, A. and Kazimir, M. (2003) Cavernous hemangioma of the cervix with intractable bleeding: A case report. Journal of Reproductive Medicine, 48, 741-743. 